\title{
LA INSERCIÓN DE LA CONCIENCIA CRÍTICA \\ EN EL MOVIMIENTO CULTURAL URUGUAYO: \\ CUESTIONAMIENTO Y RESPUESTAS \\ AL ACONTECER HISTÓRICO
}

\author{
POR \\ CARLOS ZUBILLAGA \\ Universidad de la República, Montevideo
}

El advenimiento del Uruguay al siglo XX estuvo presidido por una doble circunstancia política: el fin de las guerras civiles (1904) y el inicio de la experiencia reformista que impulsara José Batlle y Ordóñez hasta el fin de la tercera década (1905-1929). El país se convirtió entonces en un "paradigma de modernización": sin problemas étnicos significativos, con un grado estimable de justicia social, sin rupturas institucionales traumáticas, con preocupación creciente por la universalización de la enseñanza. Incluso el problema religioso, que tuvo manifestaciones de cierta virulencia hasta 1918, fue resuelto con "moderación" en 1919: "Iglesia libre en el Estado libre", se proclamó entonces; y la separación de dos espacios independientes (el de la sociedad civil secularizada y el del mundo eclesial como suma de experiencias personales de fe) pareció configurar el "descubrimiento" de cómo debían ordenarse modernamente las áreas tradicionalmente conflictivas de una sociedad.

La conformación étnico-cultural del país (su propensión cosmopolita) evidenciaba el fuerte impacto de la inmigración masiva de origen europeo (principalmente italiana y española), que se había iniciado en la segunda mitad del siglo XIX. La impronta europea de ciertos caracteres definitorios de la conducta individual y colectiva del pueblo uruguayo generó, en algunos sectores del pensamiento nacional, un equívoco sentido de ajenidad cultural, traducido en la insustancial remisión a los modelos y las novedades metropolitanos y en un paralelo desprecio por los componentes latinoamericanos de la realidad local. Los códigos de auto-reconocimiento vigentes desde la segunda década de este siglo (Montevideo como la Atenas del Plata; Uruguay como la Suiza de América) dieron la pauta de una descontextualización cultural del país que se expresó complacidamente en los círculos intelectuales más gravitantes.

Puede hablarse entonces, de una cultura de autosatisfacción, dominante hasta principios de los '30. Escasamente crítica, francamente europeizada, hecha a la medida de una sociedad en la que gravitaba con fuerza la clase media de origen inmigrante. En un país pequeño, de escasa incidencia en el mercado mundial, sofocado por vecindades poderosas e históricamente hostiles a su 
independencia, la búsqueda de un perfil cultural "propio", aunque éste resultara una mala duplicación del modelo europeo, pareció suficiente.

Demás está decir que un proyecto cultural de esta naturaleza resultó tributario del favor oficial. A este respecto quizás nada ejemplifique mejor la inanidad de semejante propuesta que los frutos de la labor de la Comisión Nacional del Centenario (de la primera Constitución, de 1830), en especial el "plan Reyles": una heteróclita suma de ensayos que pretendió ser una síntesis de la producción cultural y que se elaboró a partir de los textos de una serie de conferencias dictadas en el paraninfo de la Universidad de la República, sobre la base de un plan elaborado por Carlos Reyles. ${ }^{1}$ La complacencia por lo logrado en cien años de vida organizada y la radical ausencia de una conciencia critica fueron sus rasgos fundamentales.

La crisis del sistema capitalista mundial comenzó a manifestarse en Uruguay hacia 1931. Los postreros intentos del reformismo batllista resultaron insuficientes para detener la crisis, y junto con la pérdida del bienestar social que (de alguna forma) el Estado había asegurado hasta entonces, el país asistió a la pérdida de su normalidad institucional. El golpe de Estado de 1933 no fue sólo el ajuste de cuentas conservador al reformismo, sino el inicio de una regresión en el plano de las relaciones sociales, que en cierta medida no ha dejado aún de manifestarse.

La sociedad uruguaya sufrió de allí en más la quiebra de sus mitos y ello contribuyóa sensibilizarla, al tiempoque comenzaba a descender hacia realidades menos olímpicas. Por esa razón (amén de otras no menos significativas, como la conformación inmigratoria de su base demográfica) el pueblo uruguayo se solidarizó tan firmemente con la República Española y vivió con intensidad inusual el primer acto de la lucha antifascista que fue la Guerra Civil entre 1936 y 1939.

En el plano cultural comenzó a operarse un cambio relevante. Con el deterioro del sistema político (de su dimensión formalmente liberal) corrió pareja la revisión de las concepciones culturales dominantes y se registró el avance de una conciencia crítica que, advirtiendo la condición latinoamericana del país, se dio a trastrocar los parámetros estimativos y a buscar (de manera urgida) las claves interpretativas de la realidad. Naciólo que Angel Rama llamó la "generación crítica" (o de Marcha, en alusión al papel que el semanario de Carlos Quijano habría de jugar en la vehiculización de sus inquietudes y propuestas).

El movimiento cultural uruguayo desembocó en su etapa de revisión con un alto componente de actitud "parricida". Esa "cultura del cuestionamiento" no dejó de ser elitista en su formulación, aunque se sintiera conmovida por las situaciones de las mayorías en el país y en el continente; por ello, quizás, se

${ }^{1}$ Historia sintética de la literatura uruguaya. Plan de Carlos Reyles aprobado por la Comisión Nacional del Centenario 1830-1930 (Montevideo, Vila), 3 volúmenes. 
pensó autárquica y reclamó (como timbre de orgullo) el alejamiento de los ámbitos oficiales, su "des-estatización". En este marco surgieron experiencias del tipo de las del teatro independiente (1937: Teatro del Pueblo), que habría de reivindicar precisamente como rasgo sustantivo su plena autonomía de "toda sujeción comercial, de toda ingerencia estatal limitativa, de toda explotación publicitaria, de todo interés particular de grupos o personas, de toda presión que obstaculice la difusión de la cultura, enten dida como ingrediente de la liberación individual y colectiva".

Esta "cultura del cuestionamiento" advirtió la profundidad de la crisis que el país enfrentaba y tradujo esa advertencia en un tono crítico por momentos exasperante. Tuvo mucho de "prédica en el desierto" (a veces identificada con descreimiento generacional o con resentimiento clasista), aunque contribuyó a remover en sucesivas generaciones de uruguayos las prácticas complacientes heredadas y a mirar de frente realidades hasta entonces escamoteadas. El semanario independiente Marcha fue el principal vehículo de esta empresa cuestionadora. Sus páginas (desde la editorial hasta la de crítica de espectáculos) se caracterizaron por remover esquemas, por interrogar persistente (a veces obsesivamente) sobre la causalidad de los problemas que afectaban a la sociedad uruguaya. De allí que el signo identificador de esta etapa de la cultura uruguaya haya sido el ejercicio de la crítica, sin perjuicio de que en algunas áreas se alcanzaran logros relevantes en el plano de la creación (en la narrativa, por ejemplo).

Paralelamente a esta exacerbación del cuestionamiento, el Estado intentó redimensionar su participación en el terreno cultural. Se trató de alentar (entre 1946 y 1957) una política de bienestar, bajo la acción de un neo-reformismo de menos espesura ideológica que el de principios de siglo. Al calor de este impulso se reestructuró el Servicio Oficial de Difusión Radioeléctrica (sumando a la labor de radiodifusión, la actividad orquestal, la promoción del ballet y de la ópera, la difusión del cine-arte); se creó en 1947 la Comedia Nacional (brindando un espacio renovador al arte escénico, de la mano tutora de Margarita Xirgu); y se fundó la Facultad de Humanidades y Ciencias (a partir de un proyecto de Carlos Vaz Ferreira, dirigido a promover a nivel universitario el saber "desinteresado", en tanto contrapeso a las concepciones profesionalistas imperantes en la enseñanza superior).

Sobre fines de la década de los '50 la Universidad de la República dio un salto cualitativo al obtener la sanción de su Ley Orgánica (1958), que a la par de consagrar su plena autonomía técnica, instituyó el co-gobierno integral (docentes, estudiantes y egresados) y dispuso que su función no se reducía a capacitar profesionalmente y a "impulsar y proteger la investigación científica", sino que implicaba "contribuir al estudio de los problemas de interés general y propender a su comprensión pública [...], defender los valores morales y los principios de justicia, libertad, bienestar social, los derechos de la persona humana y la forma democrático-republicana de gobierno". La Universidad se 
transformó entonces en un activo agente de la cultura de cuestionamiento. Sufrió por ellos aislamiento, retaceo presupuestal y, finalmente, agresión y pérdida de su autonomía (1973-1984).

El gran cimbronazo continental que significó la revolución cubana operó sobre la realidad cultural uruguaya potencializando los perfiles críticos. Su aureola (casi mágica) de prestigio incendió ciertos cauces expresivos y sesgó los análisis científico-sociales (de manera, en muchos casos, inmadura). Por esos años la crisis socio-política del Uruguay se tornó inocultable, en tanto que las opciones intentadas para superarla resultaron ineficaces, tardías o utópicas. El cambio estructural que el país requería (y que con inusual sinceridad para una entidad tecnocrática como la Comisión de Inversiones y Desarrollo Económico - CIDE-, había sido planteado como inexcusable en 1965) no estaba en los planes de los agentes hegemónicos del sistema político, y resultabainalcanzable para las fuerzas progresistas que desde el pano sindical (Convención Nacional de Trabajadores - CNT), desde el político-partidario (izquierda finalmente coaligada en el Frente Amplio: 1971) o desde el de la acción directa (Movimiento de Liberación Nacional -Tupamaros), se lo proponían mediante estrategias en plazos no siempre concurrentes y por momentos contradictorios.

Fracasada en 1967 la propuesta de un desarrollismo de tono dirigista, el triunfo de las soluciones fondomonetaristas se articuló sobre la ingerencia creciente de los grupos empresariales en el aparato gubernamental. El sistema político presenció entonces un descaecimiento acelerado del papel protagónico de los partidos y una correlativa hegemonia de los grupos de intereses que volcaron la acción de gobierno a la aplicación de medidas de alto costo social (devaluación monetaria, congelación salarial, rechazo sistemático de los reclamos populares), encontrando en las fuerzas armadas un gesto bien dispuesto.

$\mathrm{El}$ agotamiento de las salidas políticas para una crisis que desnudaba la condición dependiente de la base económica nacional concluyó con la aplicación del proyecto conservador en su más deshumanizada expresión: neoliberalismo económico y dictadura militar (bajo las hopalandas protectoras de la doctrina de la seguridad nacional).

Los once años que siguieron al golpe de Estado de 1973 se caracterizaron por situaciones críticas a nivel socio-económico. En particular, la población trabajadora vivió una dramática situación signada por un índice de desocupación creciente, por la caída del salario real, y por la pérdida del poder adquisitivo; todo lo que se tradujo en serias dificultades para cubrir las necesidades básicas de las familias (vivienda, salud, alimentación y educación). La redistribución del ingreso, que significó un acentuadoempobrecimiento delos sectores populares, sólo fue posible en un contexto político autoritario en el cual esos estratos se encontraron despojados de todo canal de expresión y de todo mecanismo reivindicativo. El conflicto social declarado estuvo ausente en el Uruguay de esos años; las mayorías perjudicadas sufrieron en silencio y aislamiento la pérdida progresiva de sus posibilidades económicas, culturales y sociales. 
El movimiento cultural uruguayo del periodo autoritario fue absolutamente marginal. No sólo careció de apoyo oficial alguno, sino que resultó no pocas veces sancionado, censurado y reprimido. Fue el tramo que podríamos denominar como "cultura del desgarramiento", caracterizada por la renovación de las interrogantes (la desconfianza frente a los esquemas maniqueos, la indagación pertinaz de las raíces de la crisis, la constatación de las desazones colectivas, una como nostalgia por lo que fue). Este proceso cultural se desarrolló en un complejo relacionamiento entre agentes que operaron desde las "islas de libertad" que el régimen dictatorial hubo de permitir (malgrado sus intenciones represoras), desde la reclusión y el silencio del interior, y desde la diáspora del exilio y la emigración.

Hubo en esa cultura del desgarramiento cuatro espacios que resultaron fundamentales para seguir alentando en el país la conciencia crítica. En primer término, las pequeñas editoriales privadas independientes, que continuaron difundiendo la obra de creación de narradores y poetas - consagrados o noveles - y apostaron a su vez a privilegiar la difusión del conocimiento científico-social, en especial el historiográfico. Anualmente (en el mes de diciembre) estas editoriales entraban en contacto con el gran público en la Feria Nacional de Libros y Grabados, instancia cultural autogestionaria en la que confluían las más diversas expresiones artísticas y comunicativas (teatro, plástica, títeres, recitales poéticos, muestras cinematográficas, debates, conciertos), configurando una válvula de escape a la censura y a la postración de la política cultural del Estado.

En segundo lugar, ciertos espacios radiotelefónicos que bajo el rótulo de "comunicación periodística" integraban opiniones plurales, planteaban temas que suponían la crítica al sistema, abrían canales de información hacia el exterior; en síntesis, "refrescaban"la industria cultural de más amplia cobertura nacional.

En tercer término, la "Cinemateca Uruguaya" (fundada en 1952 con el fin de conservar los mejores filmes que se exhibían en el medio), que evolucionó hasta configurar la manifestación cultural no oficial y sin fines de lucro más importante del país. Sorteando los problemas derivados de la distribución comercial, puso al público en contacto con la mejor producción mundial, enfatizando los aportes latinoamericanos y tercermundistas, así como las expresiones de renovación y vanguardia; extendió, asimismo, la difusión de su material a los barrios montevideanos, dictó cursos especializados, e incursionó en la producción filmica.

En cuarto lugar, los centros privados de investigación y capacitación en ciencias sociales (Centro Latinoamericano de Economía Humana -CLAEH; Centro de Investigaciones y Estudios Sociales del Uruguay - CIESU; Centro de Investigaciones Económicas - CINVE; Centro Interdisciplinario de Estudios sobre el Desarrollo-Uruguay - CIEDUR), que orientaron su labor hacia la acción social concebida como la actividad desarrollada con la finalidad de promover el 
cambio social, tendiendo a la instauración de un "modelo" o utopía" de sociedad explícito o implícito. Estas instituciones, autogestionadas por los propios científicos sociales, no fueron simples reservorios de una tarea académica que permitió - más allá de limitaciones y censuras - salvar la capacidad reflexiva en términos de "pensar la sociedad" y "especular sobre su mejoramiento", sino que constituyeron factores dinámicos en el proceso de reactivación democrática de la sociedad civil.

¿Qué sucedió a partir de 1985, cuando Uruguay comenzó a transitar la vía de su redemocratización, en un proceso todavía fuertemente mediatizado por los resabios de la experiencia autoritaria? El período dictatorial provocó cambios en el plano de las políticas culturales, que tradicionalmente habia jugado en el país a constituir una modalidad más de la acción providente del Estado y que, en consecuencia, habían generado en la sociedad el acostumbramiento a delegar el protagonismo cultural en organismos públicos, asumiéndose aquélla más como receptora que como creadora. La resistencia al autoritarismo político inhibió totalmente la participación de los mejores exponentes de la cultura nacional en los ámbitos del sector público (incluido el universitario), al tiempo que ratificó modalidades de acción cultural sostenidas mediante prácticas de autogestión, que facilitaron la libertad creadora, la intensidad comunicativa y los esfuerzos de integración más allá de las fronteras del país.

La recuperación de la institucionalidad en 1985 planteó un singular desafío en el terreno cultural: el de acercar, relacionar o -eventualmente-integrar la capacidad operativa del sector público con las realizaciones en curso en diversos niveles de la sociedad civil, ello sin desmedro de la capacidad crítica que éstas habían consagrado como rasgo esencial. Habida cuenta de los acuerdos logrados en la Concertación Nacional Programática (CONAPRO) ${ }^{2}$ en 1984-5, el Estado debió haber brindado un apoyo incondicionado a aquellas experiencias, como forma de promover una fecunda confrontación de corrientes y tendencias, que contribuyera al desarrollo del espíritu crítico y de la capacidad reflexiva y estimativa de amplios sectores de la población, al tiempo que proyectara al campo de lo cultural los supuestos del pluralismo sobre los que se intentaba asentar la recuperada democracia política.

La realidad ofreció en estos años la constatación de un camino trunco; algunos tímidos avances en la actitud del Estado frente a los agentes culturales (una "apertura" de amplio espectro en el reconocimiento de la labor creadora, un relativo rechazo a las modalidades tradicionales del "oficialismo cultural"), más referidos a las individualidades que a las experiencias grupales o colectivas, no

${ }^{2}$ El proceso de salida de la dictadura tuvo en la CONAPRO su más alto grado de integración político-social. Conformada por los partidos políticos y por un amplio espectro de organizaciones sociales, la CONAPRO abordo el estudio de las diversas áreas de la realidad nacional, intentando obtener "consensos de salida" que comprometieran a los agentes políticos participantes, en sus futuras decisiones. 
alcanzaron a diseñar un relacionamiento fluido entre el sector público y el sector privado.

Por su parte las organizaciones de autogestión cultural, sometidas a un deterioro de su potencial comunicativo en razón de las dificultades económicas que afectan a los sectores asalariados de la población (en los que reclutan tanto a sus gestores como al mayor volumen de sus demandantes) enfrentan otros problemas, en especial, el vinculado a ciertos intentos de vanguardizar o hegemonizar partidaria (o ideológica)mente las prácticas culturales. La desconfianza gubernativaindiscriminada frente a las organizaciones culturales autónomas cobra vigor al referirse a estas modalidades de acción, que confunden opciones partidarias en la sociedad, con intervención partidaria (orgánica) en los ámbitos de reflexión, creación y difusión cultural (por naturaleza, dinámicos y plurales).

Discernir en qué medida puede el Estado diseñar y ejecutar políticas culturales no discriminatorias y de qué forma pueden los agentes culturales no gubernamentales eludir la marginalización (o la autoexclusión) de los espacios de realización en que aquellas políticas se traduzcan, es quizás el principal desafío de la cultura uruguaya, todavía condicionada por una visión maniquea de la sociedad, que es consecuencia tanto de las radicalizaciones ideológicas que la experiencia dictatorial alentó, como de la capacidad crítica exacerbada (¿mórbida?) de las concepciones que sustentaron, en su momento, la cultura del cuestionamiento y que carecieron de suficiente dimensión propositiva. 
